Check for updates

Cite this: RSC Adv., 2017, 7, 52218

Received 4th October 2017

Accepted 30th October 2017

DOI: 10.1039/c7ra10932f

rsc.li/rsc-advances

\section{A novel strategy to promote photo-oxidative and reductive abilities via the construction of a bipolar $\mathrm{Bi}_{2} \mathrm{WO}_{6} / \mathrm{N}-\mathrm{SrTiO}_{3}$ material $\uparrow$}

\begin{abstract}
Huayu Gu, ${ }^{a}$ Guanjie Xing, ${ }^{b}$ Huimin Gu, ${ }^{a}$ Zhanli Chai ${ }^{a}$ and Xiaojing Wang (D) *a
Focusing on holistically promoting both photo-oxidative and reductive abilities, we constructed a novel $\mathrm{Bi}_{2} \mathrm{WO}_{6} / \mathrm{N}-\mathrm{SrTiO}_{3}$ composite, which was expected to have excellent properties for the removal of complicated contaminants from solution environments under visible light irradiation. The prepared $\mathrm{Bi}_{2} \mathrm{WO}_{6} / \mathrm{N}-\mathrm{SrTiO}_{3}$ was assembled from massive $\mathrm{N}-\mathrm{SrTiO}_{3}$ nanoballs segmented via $2 \mathrm{D}$ interlaced nanosheets of $\mathrm{Bi}_{2} \mathrm{WO}_{6}$. $\mathrm{N}-\mathrm{SrTiO}_{3}$ on its own has good reductive ability and can easily reduce $\mathrm{Cr}(\mathrm{VI})$ ions, while $\mathrm{Bi}_{2} \mathrm{WO}_{6}$ has been demonstrated to have good oxidative ability to oxidize tetracycline under visible light irradiation. Importantly, mixed contaminants ( $\mathrm{TC}$ and $\mathrm{Cr}^{6+}$ ions) could be completely removed under visible light by the assembled $\mathrm{Bi}_{2} \mathrm{WO}_{6} / \mathrm{N}-\mathrm{SrTiO}_{3}$ material. It is proposed that the holes lying at the valence band of $\mathrm{N}-\mathrm{SrTiO}_{3}$ are the main active species for the oxidation of tetracycline, while the electrons located at the conduction band of $\mathrm{Bi}_{2} \mathrm{WO}_{6}$ are mainly responsible for the reduction of $\mathrm{Cr}(\mathrm{VI})$ ions. The matched band structures of $\mathrm{Bi}_{2} \mathrm{WO}_{6}$ and $\mathrm{N}-\mathrm{SrTiO}_{3}$ were beneficial for inhibiting the recombination of electron-hole pairs and maintaining the redox capacity through a Z-type $n-n$ heterojunction. Such a bipolar design of photo-oxidative and photo-reductive semiconductor nanomaterials is concluded to be highly effective in remediating complicated toxic residual constituents of both unfixed pharmaceuticals and heavy metals in aquatic environments.
\end{abstract}

\section{Introduction}

Pollutants at low concentration but of high toxicity, such as antibiotic residues or heavy metal ions, have been increasingly found over recent years in aqueous environments and have been a subject of special concern. ${ }^{1-3}$ They are potentially dangerous to ecosystems, and especially to human health, through drinking water and the food chain. ${ }^{4,5}$ For example, many antibiotics can easily enter into the environment because of their poor absorption, low metabolism, abuse and overuse. The main issues lie in the large variety and quantities of both antibiotics and their intermediates present in the environment, which makes their remediation more difficult. ${ }^{6,7}$ Aqueous heavy metal ions, being a common component of industrial waste with notoriously toxic, mutagenic and carcinogenic properties, could also lead to the deterioration of environmental quality and pose an acute threat to human health. ${ }^{8-10}$ To summarize, the complexity of pollutants in water effluents means that it is imperative to develop an efficient technique that can

${ }^{a}$ School of Chemistry and Chemical Engineering, Inner Mongolia University, Hohhot, Inner Mongolia,010021, P. R. China.E-mail:wang_xiao_jing@hotmail.com ${ }^{b}$ School of Chemistry, Beijing Normal University, Beijing, 100875, P. R. China $\dagger$ Electronic supplementary information (ESI) available. See DOI: 10.1039/c7ra10932f simultaneously remove these residual antibiotics and heavy metals, rather than any single component. ${ }^{11,12}$

The semiconductor photocatalytic removal of toxic pollutants is considered to be the most promising strategy applicable, with the advantages of low cost, no secondary pollution, low energy consumption and environmental friendliness via the utilization of solar light. ${ }^{13,14}$ Most of the photocatalytic systems only focus on a single function, either oxidative degradation or reductive elimination. However, in terms of practicality, the complexity of the pollutants that need to be removed inevitably leads to high requirements for photocatalysts with both outstanding oxidation and reduction properties. Therefore, there is an urgent need to find novel materials with excellent performance to completely eliminate mixed toxic residuals. Energetics dictates that for a semiconductor to be photochemically active, the oxidative potential of the photogenerated hole in the valence band must be sufficiently positive and the reductive potential of the conduction band electron must be sufficiently negative. ${ }^{15}$ Although a single semiconductor with a big enough band gap may exhibit special redox abilities, the wide visible light response has inevitably to be sacrificed. ${ }^{16,17}$ Another restriction in semiconductor photocatalysis is the relatively low value of the overall quantum efficiency, mainly due to the high recombination rate of photo-excited electronhole pairs. To address these issues, the appropriate assembly of constituent semiconductors is believed to be one of the most 
efficient strategies. ${ }^{\mathbf{1 8 , 1 9}}$ The electron-hole separation could be well enhanced by transferring electrons from a material with a high Fermi level to another material with a low Fermi level when they contact each other. Unfortunately, the oxidative potentials (and/or reductive potentials) are bound to increase (and/or decrease) to establish a thermodynamic equilibrium with the same Fermi level of the semiconductors at the interface. ${ }^{\mathbf{2 0 , 2 1}}$ Thereby, at present, uniting a broad spectrum of redox capabilities, visible light response, and recycling stability for composite fabrication is a still crucial challenge.

Strontium titanate (STO) has been used as one type of highly efficient photocatalyst, due to its outstanding optical and electrical performance, good conductivity and remarkable photochemical stability. ${ }^{22} \mathrm{SrTiO}_{3}$ is a semiconductor with a wide band gap and its conductive band potential is about $-0.4 \mathrm{eV}$, indicating its good reductive properties. ${ }^{23,24}$ Through nitrogen doping $\left(\mathrm{N}-\mathrm{SrTiO}_{3}\right)$, its disadvantage of a narrower adsorption region of the solar light spectrum was significantly improved. ${ }^{25}$ It has been well proven that $\mathrm{N}_{-} \mathrm{SrTiO}_{3}$ can efficiently reduce $\mathrm{Cr}(\mathrm{vI})$ ions under visible light. However, the recombination rate of the photoinduced electron-hole pairs in $\mathrm{N}_{-} \mathrm{SrTiO}_{3}$ was faster than surface reductive reactions, leading to its deactivation after a few cycles. Moreover, the performance of $\mathrm{N}-\mathrm{SrTiO}_{3}$ for the oxidation of organic pollutants is still far from satisfactory. On the other hand, Bi-based semiconductor materials, such as $\mathrm{Bi}_{2} \mathrm{O}_{3}, \mathrm{Bi}_{4} \mathrm{Ti}_{3} \mathrm{O}_{12}, \mathrm{Bi}_{2} \mathrm{WO}_{6}$, and $\mathrm{Bi}_{2} \mathrm{MoO}_{6}$, as novel kinds of photocatalysts have attracted much attention because of their layer structures and excellent catalytic properties. In particular, n-type semiconductor bismuth tungstate $\left(\mathrm{Bi}_{2} \mathrm{WO}_{6}\right)$, with a valence band (VB) potential of $2.94 \mathrm{eV}$ and a conduction band (CB) potential of $0.24 \mathrm{eV}$, is most interesting as a visible-lightresponsive photocatalyst for the oxidative degradation of organic pollutants, owing to its excellent oxidation ability. ${ }^{\mathbf{2 6 - 2 9}}$ According to a recent report from Zhou et al., ${ }^{30}$ monolayer $\mathrm{Bi}_{2} \mathrm{WO}_{6}$ with a sandwich substructure serves as a layered heterojunction with holes generated on its active surface layer, leading to outstanding photocatalytic oxidative performance with good separation of electron-hole pairs. Huang et al. ${ }^{31}$ also found that under visible light irradiation, $\mathrm{Bi}_{2} \mathrm{WO}_{6}$ could exhibit obvious photo-oxidative activity in pollutant degradation. A disadvantage of this nanomaterial is its poor reductive ability, due to the small negative potential of the conduction band.

In terms of their individual characteristics, the skilful incorporation of $\mathrm{N}-\mathrm{SrTiO}_{3}$ and $\mathrm{Bi}_{2} \mathrm{WO}_{6}$ may produce enhanced redox ability under visible light irradiation and efficiently accelerate electron-hole pair separation due to their matched band structure. In this work, a series of $n-n$ heterojunctions of $\mathrm{Bi}_{2} \mathrm{WO}_{6} / \mathrm{N}-\mathrm{SrTiO}_{3}$ were successfully prepared through a two-step hydrothermal method. The removal rate of tetracycline, as a model sample for photocatalytic oxidation over the samples, was tested, while $\mathrm{Cr}(\mathrm{vI})$ ions were used as a model for the reductive ability. The redox abilities were further evaluated by simultaneous tetracycline oxidation and $\mathrm{Cr}(\mathrm{vI})$ ion reduction under visible light irradiation. Finally, a possible mechanism for the removal of mixed pollutants over $\mathrm{Bi}_{2} \mathrm{WO}_{6} / \mathrm{N}-\mathrm{SrTiO}_{3}$ was proposed.

\section{Experimental}

\section{Material preparation and characterization}

Preparation of $\mathrm{N}-\mathrm{SrTiO}_{3}$. The reagents were all analytical grade and used without further purification. $\mathrm{N}-\mathrm{SrTiO}_{3}$ powder was prepared using a hydrothermal method. The detailed procedure was provided in our previous work. ${ }^{25}$

Preparation of $\mathbf{B i}_{2} \mathbf{W O}_{6} / \mathbf{N}-\mathrm{SrTiO}_{3} \cdot \mathrm{Bi}_{2} \mathrm{WO}_{6} / \mathrm{N}-\mathrm{SrTiO}_{3}$ powder was prepared using a hydrothermal method. A certain amount of $\mathrm{Bi}\left(\mathrm{NO}_{3}\right)_{3} \cdot 5 \mathrm{H}_{2} \mathrm{O}$ was dissolved in $17 \mathrm{~mL}$ of deionized water, and $\mathrm{Na}_{2} \mathrm{WO}_{4} \cdot 2 \mathrm{H}_{2} \mathrm{O}$ was added to the above solution according to a molar ratio of $2: 1$. Then, $1 \mathrm{~mL}$ of $\mathrm{HNO}_{3}\left(1 \mathrm{~mol} \mathrm{~L}^{-1}\right)$ was further added to the above mixture under magnetic stirring. Afterward, a certain amount of $\mathrm{N}-\mathrm{SrTiO}_{3}$ was added to the solution and stirring was continued for another $30 \mathrm{~min}$. After that, the mixture was transferred into a Teflon-lined autoclave. The autoclave was sealed and maintained at $150{ }^{\circ} \mathrm{C}$ for $24 \mathrm{~h}$. After cooling to room temperature in air naturally, the mixture was centrifuged and washed with distilled water and ethanol several times and then dried in air at $60{ }^{\circ} \mathrm{C} .{ }^{32}$ The mass ratio of $\mathrm{Bi}_{2} \mathrm{WO}_{6}$ to $\mathrm{N}-\mathrm{SrTiO}_{3}$ was set as $5,8,10,15$, and $20 \%$, and the obtained samples were correspondingly labelled as $\mathrm{Bi}_{2} \mathrm{WO}_{6} /$ NSTO5, $\mathrm{Bi}_{2} \mathrm{WO}_{6} / \mathrm{NSTO} 8, \mathrm{Bi}_{2} \mathrm{WO}_{6} / \mathrm{NSTO}_{10}, \mathrm{Bi}_{2} \mathrm{WO}_{6} / \mathrm{NSTO} 15$ and $\mathrm{Bi}_{2} \mathrm{WO}_{6} / \mathrm{NSTO} 20$, respectively.

Characterization. The phase structures and particle sizes of all of the as-prepared samples were characterized by X-ray power diffraction (XRD, PANalytical Empyream) with a copper gun. Samples morphologies were obtained using scanning electron microscopy (SEM), transmission electron microscopy (TEM) and high-resolution transmission electron microscopy (HRTEM) on a HITACHI S-4800 apparatus and a Tecnai G2F20STWIN apparatus with an acceleration voltage of $200 \mathrm{kV}$, respectively. A Perkin Elmer IR spectrometer was used to measure the frequencies of vibrations of surface groups of the as-prepared samples. The specific surface areas were determined from the nitrogen absorption data at liquid nitrogen temperature using the Barrett-Emmett-Teller (BET) technique on a Micromeritics ASAP 2000 Surface Area and Porosity Analyzer. Energy dispersive X-ray energy spectroscopy (EDS) was performed at an acceleration voltage of $20 \mathrm{kV}$ on a HITACHI S4800 apparatus. X-ray photoelectron spectroscopy (XPS) measurement was performed on a Thermo ESCALAB 250 with $\mathrm{Al}$ $\mathrm{K} \alpha(1486.6 \mathrm{eV})$ line at $150 \mathrm{~W}$. To compensate for surface charge effects, the binding energies were calibrated using the $\mathrm{C} 1 \mathrm{~s}$ peak at $284.60 \mathrm{eV}$ as a reference. A diffusive reflectance UV-vis spectrophotometer (UVIKON XL/XS) was used to measure the diffuse reflectance spectra of the samples. $\mathrm{BaSO}_{4}$ was taken as a reference, and the spectra were recorded in the range of 190-800 $\mathrm{nm}$. The band gap of the samples was estimated from the onset of the absorption using the formula $E_{\mathrm{g}}(\mathrm{eV})=1240 / \lambda_{\mathrm{g}}(\mathrm{nm})$. Electrochemical measurements were performed on a CHI 660D electrochemical workstation (Shanghai Chenhua, China) using a standard three-electrode cell with a working electrode, platinum wire as a counter electrode, and $\mathrm{Ag} / \mathrm{AgCl}$ in saturated $\mathrm{KCl}$ as a reference electrode. Electrochemical impedance spectroscopy (EIS) was carried out at the open circuit potential. The 
amplitude of the sinusoidal wave was $5 \mathrm{mV}$, and frequency range was from $100 \mathrm{kHz}$ to $0.1 \mathrm{~Hz}$. During all measurements, the electrolyte was $0.2 \mathrm{M} \mathrm{Na}_{2} \mathrm{SO}_{4}$. The charge transfer resistance of the materials was calculated by fitting the impedance data from the equivalent circuit using EIS.

\section{Photocatalytic activity evaluation}

The photocatalytic activities of the as-prepared samples were evaluated by tetracycline oxidation and $\operatorname{Cr}(\mathrm{vI})$ ion reduction. Tetracycline (TC) degradation was tested in a XPA-7 photochemical reactor containing $30 \mathrm{mg}$ of catalyst sample and $100 \mathrm{~mL}$ of $20 \mathrm{mg} \mathrm{L}^{-1}$ tetracycline aqueous solution, which was adjusted to $\mathrm{pH}=1$. A $300 \mathrm{~W} \mathrm{Hg}$ lamp with a UV-cutoff filter $(\lambda>400 \mathrm{~nm})$ was placed inside the reactor. Water was circulated through the annulus to avoid heating during the reaction. The suspension was stirred continuously for $120 \mathrm{~min}$ in the dark to establish an equilibrium of tetracycline hydrochloride absorption/desorption on the samples before light irradiation. At certain time intervals, $4 \mathrm{~mL}$ of solution was centrifuged to investigate the changes in the absorption peak using a UVIKON $\mathrm{XL} / \mathrm{XS}$ spectrometer and this was used to determine the concentration of TC. The photocatalytic degradation rate $\left(D_{\mathrm{r}}\right)$ was calculated using the following equation:

$$
D_{\mathrm{r}}=\frac{C_{0}-C_{t}}{C_{0}} \times 100 \%
$$

where $C_{0}$ is the initial concentration of tetracycline solution and $C_{t}$ is the concentration at irradiation time $t$.

$\mathrm{Cr}(\mathrm{vI})$ ion reduction was evaluated by analyzing the decreased concentration of $\mathrm{Cr}(\mathrm{vI})$ ions in the solution. $30 \mathrm{mg}$ of catalyst sample was added into a $\mathrm{K}_{2} \mathrm{Cr}_{2} \mathrm{O}_{7}$ aqueous solution (5 $\mathrm{mg} \mathrm{L}^{-1}$ ) together with the color-developing agent diphenylcarbazide (DPCI). The mixture solution was kept for $60 \mathrm{~min}$ in the dark, with constant stirring, to reach adsorption equilibrium. The reduction rate can be calculated according to the above eqn (1).

The synergic effect of removing both tetracycline and $\mathrm{Cr}(\mathrm{vI})$ ions was measured with similar photocatalytic activity experiments, by simultaneous degradation of a mixed solution containing tetracycline $\left(20 \mathrm{mg} \mathrm{L}^{-1}\right)$ and $\mathrm{Cr}(\mathrm{vI})$ ions $\left(5 \mathrm{mg} \mathrm{L}^{-1}\right)$ over $0.3 \mathrm{mg} \mathrm{L}^{-1}$ catalyst samples. The reactive active species were detected using trapping experiments. The process was similar to the above photodegradation experiments.

\section{Results and discussion}

Fig. 1 shows the XRD patterns of $\mathrm{Bi}_{2} \mathrm{WO}_{6} / \mathrm{NSTO} 10$ together with $\mathrm{Bi}_{2} \mathrm{WO}_{6}$ and $\mathrm{N}-\mathrm{SrTiO}_{3}$. The diffraction peaks of the $\mathrm{Bi}_{2} \mathrm{WO}_{6} /$ NSTO10 composite were well matched to the standard values of the cubic phase of $\mathrm{SrTiO}_{3}$ (ICOD no. 01-089-4934) and the tetragonal phase of $\mathrm{Bi}_{2} \mathrm{WO}_{6}$ (ICOD no. 01-079-2381). In addition, the characteristic peaks of $\mathrm{Bi}_{2} \mathrm{WO}_{6}$ were all weak in intensity in the as-prepared composites with different weight ratios of $\mathrm{W}: \mathrm{Ti}=5 \%, 8 \%, 10 \%, 15 \%$, and $20 \%$, respectively (Fig. S1 $\dagger$ ). This indicated the smaller amount of $\mathrm{Bi}_{2} \mathrm{WO}_{6}$ in the composites. $^{33}$ No other characteristic peaks were detected,

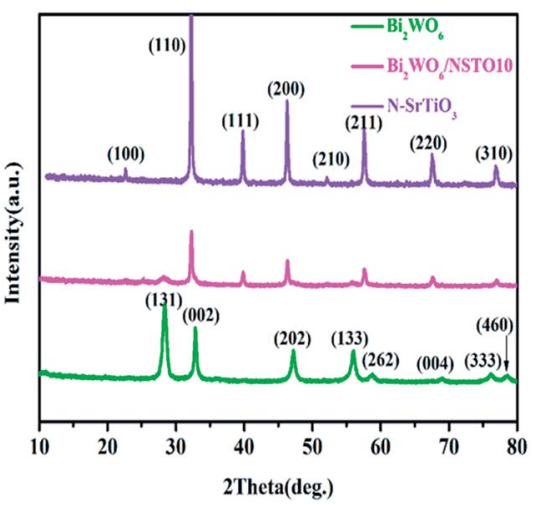

Fig. 1 XRD patterns of $\mathrm{Bi}_{2} \mathrm{WO}_{6} / \mathrm{NSTO} 10, \mathrm{Bi}_{2} \mathrm{WO}_{6}$, and $\mathrm{N}-\mathrm{SrTiO}_{3}$.

which demonstrated that $\mathrm{Bi}_{2} \mathrm{WO}_{6} / \mathrm{N}-\mathrm{SrTiO}_{3}$ composites were successfully fabricated without other impurities.

The morphologies of pure $\mathrm{Bi}_{2} \mathrm{WO}_{6}, \mathrm{~N}-\mathrm{SrTiO}_{3}$ and $\mathrm{Bi}_{2} \mathrm{WO}_{6} /$ NSTO10 were analyzed by scanning electron microscopy (SEM) and transmission electron microscopy (TEM). A good layer structure was observed visually for the prepared $\mathrm{Bi}_{2} \mathrm{WO}_{6}$, which was constructed from many 2D interlaced nanosheets (Fig. 2a). The $\mathrm{N}_{-} \mathrm{SrTiO}_{3}$ particles exhibited a sphere-like shape with an average size of 30-50 nm, as shown in Fig. 2b. Fig. 2c intuitively indicated that nanosheets of $\mathrm{Bi}_{2} \mathrm{WO}_{6}$ were evenly inserted into the massive $\mathrm{N}-\mathrm{SrTiO}_{3}$ nanoballs. The HRTEM image of $\mathrm{Bi}_{2} \mathrm{WO}_{6} /$ NSTO10 (Fig. 2d) clearly shows crystal lattice stripes with a spacing of $0.28 \mathrm{~nm}$, corresponding to the $\left(\begin{array}{lll}0 & 1 & 1\end{array}\right)$ crystal plane of $\mathrm{SrTiO}_{3}$ particles, while the lattice spacing of $0.31 \mathrm{~nm}$ was ascribed to the $\left(\begin{array}{lll}1 & 3 & 1\end{array}\right)$ crystal plane of $\mathrm{Bi}_{2} \mathrm{WO}_{6}$, in accordance with the XRD results. To further confirm the composition, the

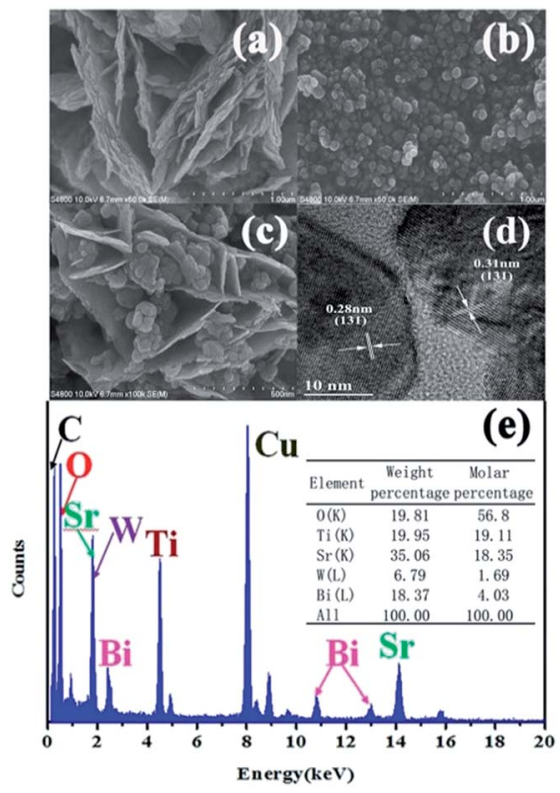

Fig. 2 SEM images of (a) $\mathrm{Bi}_{2} \mathrm{WO}_{6}$, (b) $\mathrm{N}-\mathrm{SrTiO}_{3}$, and (c) $\mathrm{Bi}_{2} \mathrm{WO}_{6} /$ NSTO10, (d) HRTEM image of $\mathrm{Bi}_{2} \mathrm{WO}_{6} / \mathrm{NSTO} 10$, and (e) EDX spectrum of $\mathrm{Bi}_{2} \mathrm{WO}_{6} / \mathrm{NSTO} 10$, and EDS element content analysis of $\mathrm{Bi}_{2} \mathrm{WO}_{6} /$ NSTO10 (inset). 
element distribution of the as-prepared composite was analyzed by energy dispersive X-ray spectroscopy (EDS) (Fig. 2e). The existence of $\mathrm{C}, \mathrm{Cu}, \mathrm{O}, \mathrm{Sr}, \mathrm{Ti}, \mathrm{Bi}$, and $\mathrm{W}$ elements was observed in the EDS data, in which the $\mathrm{C}$ element was from the carbon film and $\mathrm{Cu}$ came from the copper wire mesh. ${ }^{34} \mathrm{~N}$ was not detected, which was explained by the lower doping amount. From the inset of Fig. 2e, the atomic ratio of $\mathrm{Sr} / \mathrm{Ti}$ is calculated to be approximately $1: 1$, very close to the theoretical value of $\mathrm{SrTiO}_{3}$, while the atomic ratio of $\mathrm{Bi} / \mathrm{W}$ is calculated to be approximately $2: 1$, corresponding to the theoretical value of $\mathrm{Bi}_{2} \mathrm{WO}_{6}$. Furthermore, the atomic ratio of W/Ti is close to $1: 13$, which is in agreement with the initial molar ratio of the composite. The growth process of $\mathrm{Bi}_{2} \mathrm{WO}_{6} / \mathrm{N}-\mathrm{SrTiO}_{3}$ could be approximately deduced and is schematically represented in Fig. S2. $\dagger$ The $\mathrm{Bi}_{2} \mathrm{WO}_{6}$ nanosheets were generated immediately when $\mathrm{Bi}^{3+}$ and $\mathrm{WO}_{6}{ }^{6-}$ collided under hydrothermal reaction conditions. Then they were inserted into the massive as-prepared $\mathrm{N}_{-} \mathrm{SrTiO}_{3}$ nanospheres to construct $\mathrm{Bi}_{2} \mathrm{WO}_{6} / \mathrm{N}-\mathrm{SrTiO}_{3}$, forming accumulated nano-balls segmented by nanosheets. This construction provided more active points for the adsorption of organic pollutants and separated redox active sites to completely remove the mixed pollutants through both oxidative degradation and reductive reaction. ${ }^{35}$

To investigate the light adsorption, UV-vis diffuse reflectance spectra of $\mathrm{Bi}_{2} \mathrm{WO}_{6}, \mathrm{~N}-\mathrm{SrTiO}_{3}$, and $\mathrm{Bi}_{2} \mathrm{WO}_{6} / \mathrm{N}-\mathrm{SrTiO}_{3}$ composites with different $\mathrm{W}: \mathrm{Ti}$ ratios were measured (Fig. 3a). $\mathrm{Bi}_{2} \mathrm{WO}_{6}$ exhibited light absorption from the UV to the visible light region, with an absorption edge at about $430 \mathrm{~nm}$, which was assigned to the intrinsic band gap transition. $\mathrm{N}-\mathrm{SrTiO}_{3}$ showed
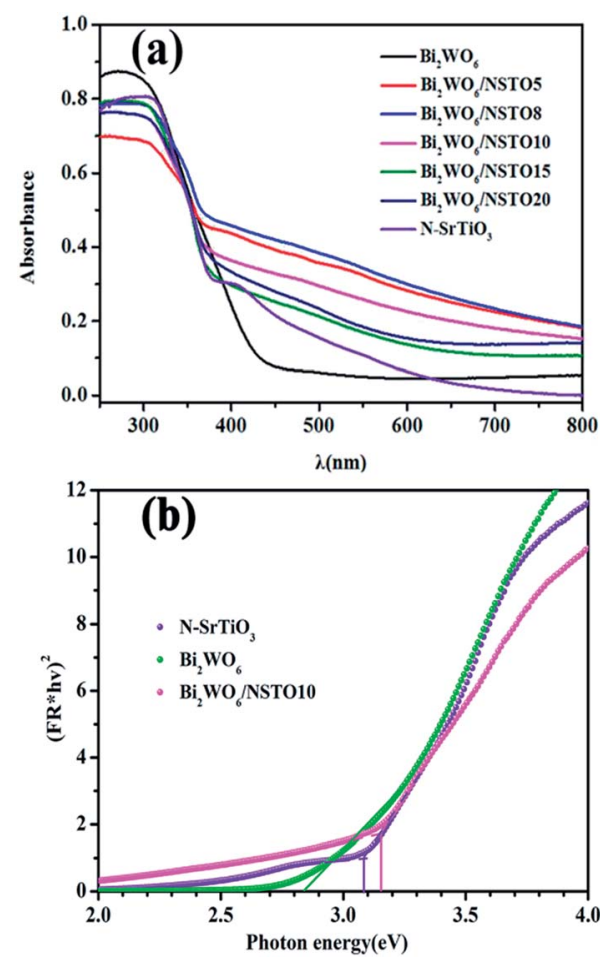

Fig. 3 (a) UV-visible diffuse reflectance spectra of the as-prepared samples, and (b) the optical bandgap of pristine $\mathrm{Bi}_{2} \mathrm{WO}_{6}$ and $\mathrm{N}-\mathrm{SrTiO}_{3}$. a strong absorption in the range of $200-400 \mathrm{~nm}$, as well as a stronger peak at around $420 \mathrm{~nm}$. The optical absorption near the band edge follows the formula $(\alpha h \nu)^{2}=A\left(h \nu-E_{\mathrm{g}}\right)$, where $\alpha$, $h, \nu, E_{\mathrm{g}}$, and A are the absorption coefficient, Planck's constant, the light frequency, the band gap, and a constant, respectively. ${ }^{36}$ The band gap energy $\left(E_{g}\right)$ is $2.83 \mathrm{eV}$ for pure $\mathrm{Bi}_{2} \mathrm{WO}_{6}$ and $3.08 \mathrm{eV}$ for $\mathrm{N}_{-} \mathrm{SrTiO}_{3}$ as estimated by extrapolating the line (Fig. 3b), consistent with a previous study. ${ }^{37,38}$ Apparently, compared with both pure $\mathrm{Bi}_{2} \mathrm{WO}_{6}$ and $\mathrm{N}-\mathrm{SrTiO}_{3}, \mathrm{Bi}_{2} \mathrm{WO}_{6} / \mathrm{N}-\mathrm{SrTiO}_{3}$ showed enhanced light absorption in the UV-vis region.

The XPS results (Fig. 4) and FT-IR spectra (Fig. S3†) provided further insight into the chemical composition and groups of the as-prepared $\mathrm{Bi}_{2} \mathrm{WO}_{6}$ and $\mathrm{Bi}_{2} \mathrm{WO}_{6} / \mathrm{NSTO} 10$. The XPS survey spectra indicated the existence of $\mathrm{Bi}, \mathrm{O}, \mathrm{W}, \mathrm{Sr}, \mathrm{Ti}$, and $\mathrm{C}$ elements in the surface of $\mathrm{Bi}_{2} \mathrm{WO}_{6} / \mathrm{NSTO} 10$ (Fig. 4a). The C $1 \mathrm{~s}$ peak at a binding energy of about $284.9-285.9 \mathrm{eV}$ is derived from the carbon tape used for fixing the sample and from atmospheric $\mathrm{CO}_{2}$ adsorbed on the sample surface. ${ }^{39}$ The highresolution $\mathrm{Bi}$ if spectra of the $\mathrm{Bi}_{2} \mathrm{WO}_{6} / \mathrm{NSTO} 10$ and pure $\mathrm{Bi}_{2} \mathrm{WO}_{6}$ samples are shown in Fig. $4 \mathrm{~b}$. Two strong peaks located at 159.2 and $164.6 \mathrm{eV}$ for both samples are attributed to $\mathrm{Bi} 4 \mathrm{f}_{7 / 2}$ and $\mathrm{Bi}_{4 \mathrm{f}_{5 / 2}}$ of $\mathrm{Bi}^{3+}$, respectively. The peaks at binding energies of 35.4 and $37.5 \mathrm{eV}$ are the signals of $\mathrm{W}_{4 \mathrm{f}_{7 / 2}}$ and $4 \mathrm{f}_{5 / 2}$ of $\mathrm{W}^{6+}$ in $\mathrm{Bi}_{2} \mathrm{WO}_{6}$ (Fig. 4c). In the same way, the binding energies of 132.6 and $134.4 \mathrm{eV}$ with a doublet separation of $1.8 \mathrm{eV}$ were assigned to $3 \mathrm{~d}_{5 / 2}$ and $3 \mathrm{~d}_{3 / 2}$ of $\mathrm{Sr}^{3+}$, respectively (Fig. $4 \mathrm{~d}$ ). ${ }^{40}$ The results indicate the consistent surface component of $\mathrm{Bi}^{3+}$ in the pure $\mathrm{Bi}_{2} \mathrm{WO}_{6}$ and $\mathrm{Bi}_{2} \mathrm{WO}_{6} / \mathrm{NSTO}$. The peaks in the FT-IR spectrum of $\mathrm{Bi}_{2} \mathrm{WO}_{6} / \mathrm{NSTO} 10$ were mainly matched with $\mathrm{N}-\mathrm{SrTiO}_{3}$ due to the enormous $\mathrm{N}_{-} \mathrm{SrTiO}_{3}$ content in the composite (Fig. S4 $\dagger$ ). However, the peak at $1633 \mathrm{~cm}^{-1}$ was stronger in the composite than in the individual component, suggesting that the hydrophilic ability of the composite was enhanced.

TC was used as a model reagent to evaluate the oxidation ability of the as-prepared samples. Fig. 5a displays the UV
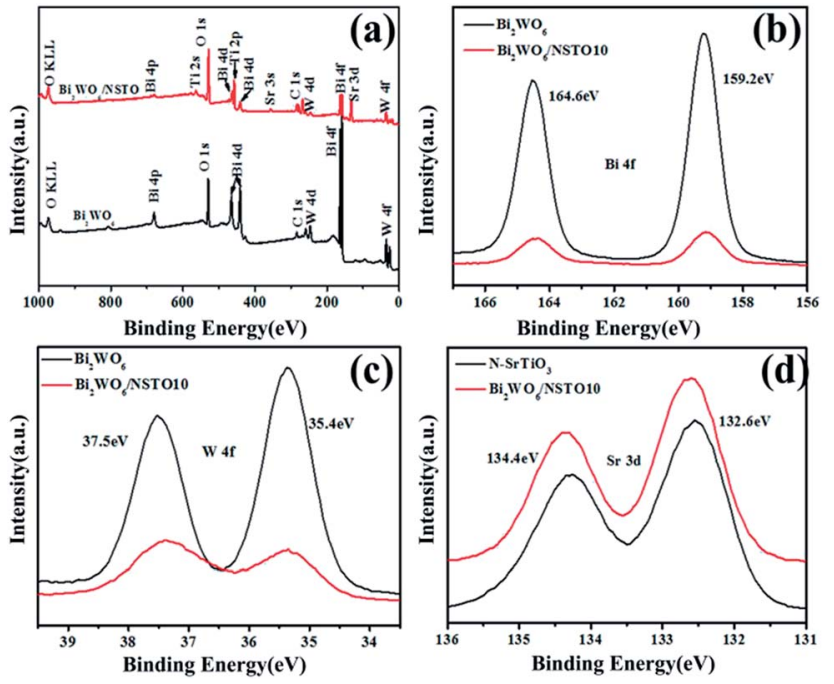

Fig. 4 The XPS spectra of $\mathrm{Bi}_{2} \mathrm{WO}_{6}$ and $\mathrm{Bi}_{2} \mathrm{WO}_{6} / \mathrm{NSTO} 10$ : (a) survey, (b) $\mathrm{Bi} 4 \mathrm{f}$ orbitals, (c) W $4 \mathrm{f}$ orbitals, and (d) $\mathrm{Sr} 3 d$ orbitals of $\mathrm{N}-\mathrm{SrTiO}_{3}$ and $\mathrm{Bi}_{2} \mathrm{WO}_{6} / \mathrm{NSTO} 10$. 

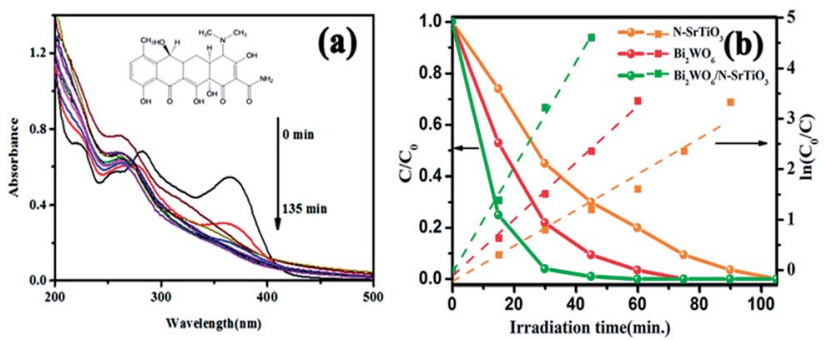

Fig. 5 (a) UV-vis absorption spectrum recorded during TC degradation over $\mathrm{Bi}_{2} \mathrm{WO}_{6} / \mathrm{NSTO} 10$ under visible light irradiation and structural formula of TC (inset). (b) Concentration of TC versus visible light irradiation time and the apparent reaction kinetic curve linear transformation.

spectra taken in the course of the photodegradation experiments of TC over $\mathrm{Bi}_{2} \mathrm{WO}_{6} / \mathrm{NSTO} 10$ under visible light illumination $(\lambda>420 \mathrm{~nm})$. There is enough time in the dark for $2 \mathrm{~h}$ to ensure the establishment of an adsorption/desorption equilibrium of TC on the catalyst surface. A rapid decrease of TC at the wavelength of $360 \mathrm{~nm}$ was observed, accompanied by an absorption band shift to a shorter wavelength of $270 \mathrm{~nm}$. The peaks at $270 \mathrm{~nm}$ and $360 \mathrm{~nm}$ corresponded to the $\mathrm{E}_{2}$ and $\mathrm{B}$ bands of the benzene ring, respectively, indicating that the sample could degrade TC into small molecules. ${ }^{41}$ In comparison with $\mathrm{Bi}_{2} \mathrm{WO}_{6}$ and $\mathrm{N}-\mathrm{SrTiO}_{3}$ in Fig. $5 \mathrm{~b}$, the conversion of $\mathrm{TC}$ was approximately $98 \%$ after $30 \mathrm{~min}$ of irradiation under visible light for $\mathrm{Bi}_{2} \mathrm{WO}_{6} / \mathrm{N}-\mathrm{SrTiO}_{3}$, higher than that of pure $\mathrm{Bi}_{2} \mathrm{WO}_{6}(79 \%)$ and $\mathrm{N}-\mathrm{SrTiO}_{3}(55 \%)$. According to the formula $\ln \left(C_{0} / C_{t}\right)=k t$, the lines were clearly well fitted with the pseudo-first-order kinetics model. The observed rate constant $(k)$ for the degradation of $\mathrm{TC}$ is $5.76 \mathrm{~h}^{-1}$ for $\mathrm{Bi}_{2} \mathrm{WO}_{6} / \mathrm{NSTO} 10$, while that for $\mathrm{N}-\mathrm{SrTiO}_{3}$ is $2.91 \mathrm{~h}^{-1}$ and that for $\mathrm{Bi}_{2} \mathrm{WO}_{6}$ is $3.68 \mathrm{~h}^{-1}$. It was proved that the oxidation of TC over $\mathrm{Bi}_{2} \mathrm{WO}_{6}$ surpassed that of $\mathrm{N}-\mathrm{SrTiO}_{3}$. More importantly, $\mathrm{Bi}_{2} \mathrm{WO}_{6} / \mathrm{NSTO} 10$ could gain an advantage over any sole component for the photocatalytic degradation of TC.

$\mathrm{Cr}(\mathrm{vI})$ ions were used as a model reagent to evaluate the reduction ability of the as-prepared samples. Fig. 6 shows the photo-reductive activities of $\mathrm{Bi}_{2} \mathrm{WO}_{6} / \mathrm{N}$-SrTiO 3 composites together with pure $\mathrm{Bi}_{2} \mathrm{WO}_{6}$ and $\mathrm{N}-\mathrm{SrTiO}_{3}$. Opposite to TC oxidation, weak reduction (only $15 \%$ ) was observed for $\mathrm{Bi}_{2} \mathrm{WO}_{6}$, whereas $\mathrm{N}_{-} \mathrm{SrTiO}_{3}$ showed a higher photo-reductive efficiency (about $58 \%$ in $40 \mathrm{~min}$ ) under visible light irradiation. Importantly, on assembling $\mathrm{Bi}_{2} \mathrm{WO}_{6}$ and $\mathrm{N}-\mathrm{SrTiO}_{3}$ (mass ratio from 5 to $10 \%), \mathrm{Bi}_{2} \mathrm{WO}_{6} / \mathrm{N}-\mathrm{SrTiO}_{3}$ showed an obviously increased photo-reductive activity; $5 \mathrm{mg} \mathrm{L}^{-1} \mathrm{Cr}(\mathrm{vI})$ ions were completely reduced in 90 min under visible light irradiation. However, it should be noted that when the mass ratio continues to increase (that is, the amount of $\mathrm{Bi}_{2} \mathrm{WO}_{6}$ becomes higher), there is a decrease in the photo-reductive activity. The kinetic rate constants under visible light were calculated (Fig. S4†). The photo-reduction of $\mathrm{Cr}(\mathrm{vI})$ ions can be fitted to a pseudo-firstorder reaction and the rate constant $\left(k_{\mathrm{ap}}\right)$ is $2.33 \mathrm{~h}^{-1}$ for $\mathrm{Bi}_{2} \mathrm{WO}_{6} / \mathrm{NSTO}^{-10}$, obviously higher than that of $\mathrm{N}-\mathrm{SrTiO}_{3}$ $\left(0.908 \mathrm{~h}^{-1}\right)$ and $\mathrm{Bi}_{2} \mathrm{WO}_{6}\left(0.155 \mathrm{~h}^{-1}\right)$. As a result, the constructed heterojunction of $\mathrm{Bi}_{2} \mathrm{WO}_{6} / \mathrm{NSTO} 10$ presented the highest photoreductive activity compared with either component.

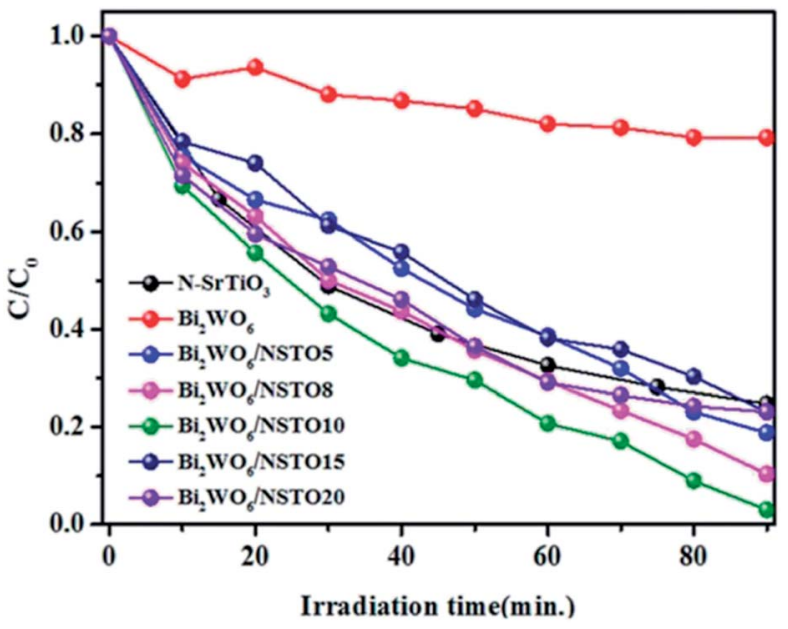

Fig. 6 Concentration of $\mathrm{Cr}(\mathrm{VI})$ versus visible light irradiation time in the presence of $\mathrm{Bi}_{2} \mathrm{WO}_{6}, \mathrm{~N}-\mathrm{SrTiO}_{3}$ and $\mathrm{Bi}_{2} \mathrm{WO}_{6} / \mathrm{N}-\mathrm{SrTiO}_{3}$ with various ratios of $\mathrm{W}: \mathrm{Ti}=5 \%, 8 \%, 10 \%, 15 \%$, and $20 \%$, respectively.

Finally, the feasibility of simultaneous tetracycline oxidation and $\mathrm{Cr}(\mathrm{vI})$ ion reduction over $\mathrm{Bi}_{2} \mathrm{WO}_{6} / \mathrm{N}-\mathrm{SrTiO}_{3}$ was tested in a simulated complicated solution that contained tetracycline and $\mathrm{Cr}(\mathrm{vI})$ ions. Firstly, the reduction rate of $\mathrm{Cr}(\mathrm{vI})$ ions in the mixed solution is shown in Fig. 7a. The $\mathrm{Cr}(\mathrm{vI})$ ions $\left(5 \mathrm{mg} \mathrm{L}^{-1}\right)$ were completely reduced in $20 \mathrm{~min}$ under visible light for the $\mathrm{Bi}_{2} \mathrm{WO}_{6} / \mathrm{NSTO} 10$ composite, which is about 2 and 10 times faster than the reaction with pure $\mathrm{N}-\mathrm{SrTiO}_{3}$ and $\mathrm{Bi}_{2} \mathrm{WO}_{6}$, respectively. Secondly, the oxidation of TC in the mixed solution is shown in Fig. $7 \mathrm{~b}$. For $\mathrm{Bi}_{2} \mathrm{WO}_{6} / \mathrm{NSTO} 10$, the oxidation of TC was accelerated in the mixture of $\mathrm{Cr}(\mathrm{vI})$ and $\mathrm{TC}$ under visible light, and up to $100 \%$ of the TC was oxidized within $20 \mathrm{~min}$, indicating about 1.45 and 2.5 times better activity than the sole
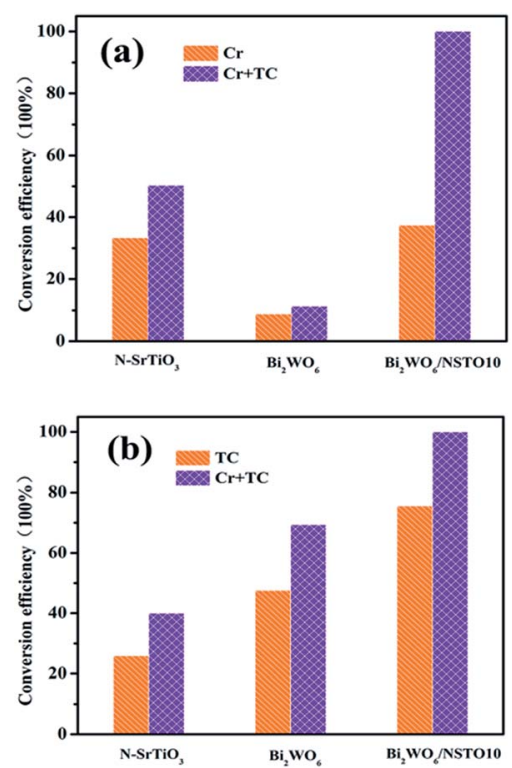

Fig. 7 (a) $\mathrm{Cr}(\mathrm{VI})$ and (b) TC conversion efficiencies in the first 20 minutes over the as-prepared photocatalysts in a single solution ( $\mathrm{TC}$ or $\mathrm{Cr}(\mathrm{VI}))$ and mixed solution (TC and $\mathrm{Cr}(\mathrm{V} \mathrm{I})$ ). 
components $\mathrm{Bi}_{2} \mathrm{WO}_{6}(69 \%)$ and $\mathrm{N}-\mathrm{SrTiO}_{3}(40 \%)$. Thirdly, all samples, $\mathrm{Bi}_{2} \mathrm{WO}_{6} / \mathrm{NSTO}_{0}, \mathrm{Bi}_{2} \mathrm{WO}_{6}$, and $\mathrm{N}-\mathrm{SrTiO}_{3}$, showed better activity for TC oxidation (or $\mathrm{Cr}^{6+}$ ion reduction) in the mixed pollutant environment than in the single pollutant solution. Thus, two conclusions were derived from the above results. (1) The integrated $\mathrm{Bi}_{2} \mathrm{WO}_{6} / \mathrm{N}-\mathrm{SrTiO}_{3}$ composite was obviously more efficient for both $\mathrm{TC}$ oxidation and $\operatorname{Cr}(\mathrm{vI})$ ion reduction than any sole component, indicating that both the oxidative and reductive performance were substantially improved through coupling design. (2) The coexistence of tetracycline and $\mathrm{Cr}(\mathrm{vI})$ ions was conducive to the removal of either constituent contaminant, confirming that the designed $\mathrm{Bi}_{2} \mathrm{WO}_{6} / \mathrm{N}-\mathrm{SrTiO}_{3}$ was absolutely superior for the removal of mixed contaminants. Besides, compared with other references regarding the photocatalytic reduction of $\mathrm{Cr}(\mathrm{vI})$ ions $^{42-45}$ and the degradation of TC, ${ }^{46-48}$ the removal efficiency of the present work showed outstanding advantages (Tables S1 and S2 $\dagger$ ).

To assess the stability of the as-prepared composite, the photocurrent under $300 \mathrm{~W}$ xenon lamp irradiation was recorded and shown in Fig. 8a. Among all the samples, $\mathrm{N}_{-} \mathrm{SrTiO}_{3}$ presented the highest photocurrent density, implying higher light harvesting. However, the photocurrent response was continuously decreased during several on-off cycles. Combining $\mathrm{Bi}_{2} \mathrm{WO}_{6}$ and $\mathrm{N}-\mathrm{SrTiO}_{3}$ into a composite, the photo-responsive phenomenon of $\mathrm{Bi}_{2} \mathrm{WO}_{6} / \mathrm{NSTO} 10$ was entirely reversible upon each light irradiation, exhibiting more excellent stability. We also conducted recycling experiments for the mixed contaminants over $\mathrm{Bi}_{2} \mathrm{WO}_{6} / \mathrm{NSTO} 10$ under visible light irradiation and
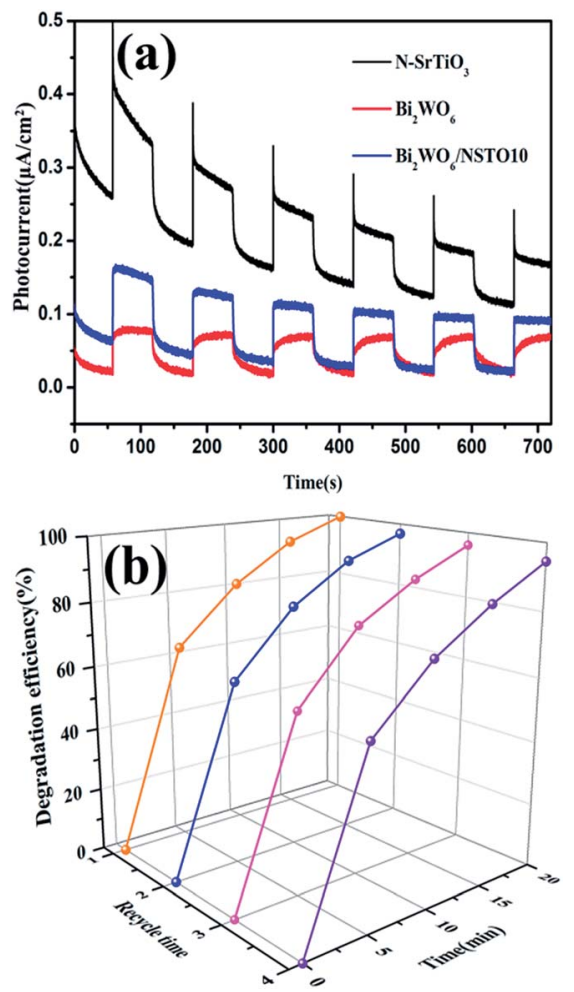

Fig. 8 (a) Photocurrent responses of $\mathrm{N}-\mathrm{SrTiO}_{3}, \mathrm{Bi}_{2} \mathrm{WO}_{6}$ and $\mathrm{Bi}_{2} \mathrm{WO}_{6} /$ NSTO10 electrodes. (b) Cycling degradation of TC in a mixed solution (TC and $\mathrm{Cr}(\mathrm{VI})$ ) using $\mathrm{Bi}_{2} \mathrm{WO}_{6} / \mathrm{NSTO} 10$. the results are illustrated in Fig. 8b. No noticeable activity change is observed during four successive cycles, suggesting that the $\mathrm{Bi}_{2} \mathrm{WO}_{6} / \mathrm{NSTO} 10$ composite is recyclable with good stability during the photocatalytic remediation of complicated toxic residuals.

As is well known, the specific surface area and porosity are important factors to enhance catalytic performance. The isotherm curves of $\mathrm{Bi}_{2} \mathrm{WO}_{6}, \mathrm{~N}_{-} \mathrm{SrTiO}_{3}$, and $\mathrm{Bi}_{2} \mathrm{WO}_{6} / \mathrm{NSTO} 10$ were characterized as type III with an $\mathrm{H}_{3}$ hysteresis loop according to Brunauer-Deming-Deming-Teller (BDDT) classification, ${ }^{49}$ as shown in Fig. 9. The BET surface area of the $\mathrm{Bi}_{2} \mathrm{WO}_{6} / \mathrm{NSTO} 10$ nanocrystals is about $31.0 \mathrm{~cm}^{3} \mathrm{~g}^{-1}$, slightly larger than the value of $27.7 \mathrm{~cm}^{3} \mathrm{~g}^{-1}$ for $\mathrm{N}-\mathrm{SrTiO}_{3}$, whereas it is obviously smaller than that of $\mathrm{Bi}_{2} \mathrm{WO}_{6}$ (inset of Fig. 9). Combined with the photocatalytic results (Fig. 8), it was deduced that the change in electron structure played a significant role in enhancing the photocatalytic performance, instead of the high BET surface area in the as-prepared composite.

Radical-trapping experiments were performed to determine the active species in TC degradation by using different scavengers, including benzoquinone ( $\mathrm{BQ}$, superoxide anion $\mathrm{O}^{2-}$ radical scavenger), tert-butanol (TBA, ${ }^{\circ} \mathrm{OH}$ radical scavenger), silver nitrate $\left(\mathrm{AgNO}_{3}\right.$, electron scavenger) and ammonium oxalate (AO, hole scavenger). ${ }^{50}$ As shown in Fig. 10, TC photodegradation was greatly restrained in the presence of $\mathrm{AO}$, compared with the reaction without radical scavengers. Furthermore, the degradation of TC was slightly decreased when TBA was added into the reaction system. These results revealed that $\mathrm{h}^{+}$plays a more significant role, while ${ }^{\circ} \mathrm{OH}$ gives a secondary contribution in TC degradation under visible light irradiation, confirming that an oxidative reaction of TC occurred for $\mathrm{Bi}_{2} \mathrm{WO}_{6} / \mathrm{NSTO} 10$ in aqueous solution.

EIS is an efficient electrochemical method to explain the electron-transfer efficiency at electrodes. ${ }^{51} \mathrm{~N}_{-} \mathrm{SrTiO}_{3}$ showed the biggest diameter, implying that it has poor electrical conductivity (Fig. 11a). In comparison, $\mathrm{Bi}_{2} \mathrm{WO}_{6} / \mathrm{NSTO} 10$ exhibited the smallest diameter, indicating a faster charge transfer shift through the composite electrode interface. This suggested a significant promotion of the photo-response ability due to the effective restraint of photo-generated charge recombination. The charge transfer resistance of the materials was obtained

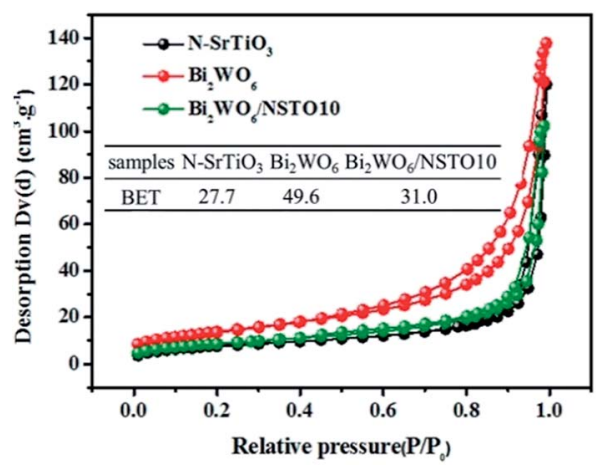

Fig. 9 Nitrogen adsorption/desorption isotherms and BET of the asprepared samples (inset). 


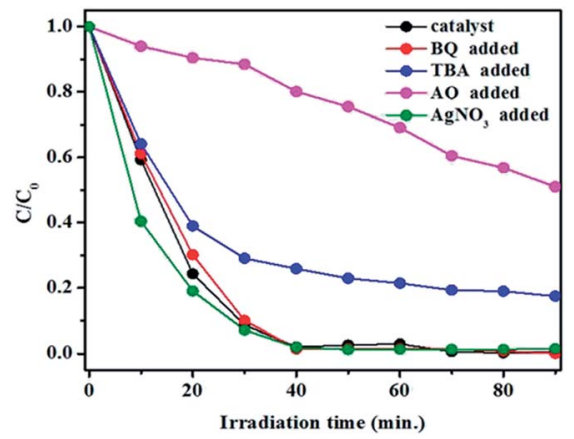

Fig. 10 Effects of different scavengers on TC degradation in the presence of $\mathrm{Bi}_{2} \mathrm{WO}_{6} / \mathrm{NSTO} 10$ under visible light irradiation.
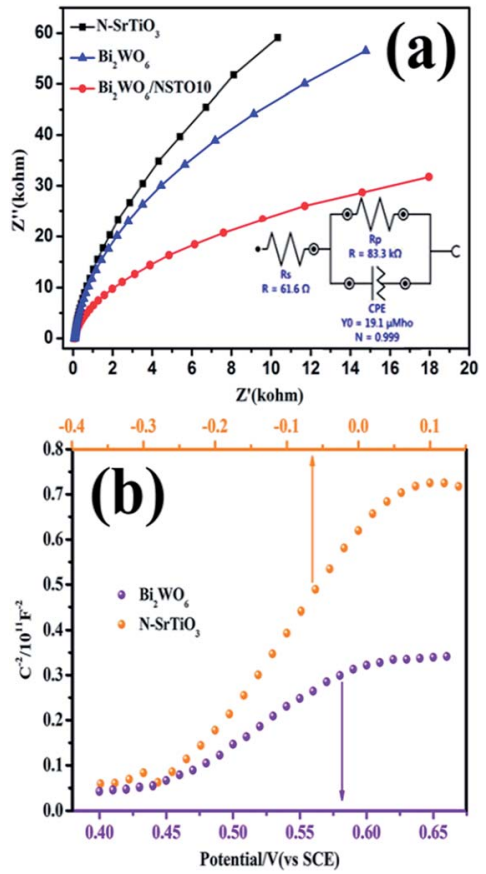

Fig. 11 (a) Electrochemical impedance spectroscopy (EIS) plots, and (b) Mott-Schottky (MS) plots of the $\mathrm{Bi}_{2} \mathrm{WO}_{6}$ and $\mathrm{N}-\mathrm{SrTiO}_{3}$ film electrodes.

from the equivalent circuit by fitting the impedance data using EIS. The fitted impedance value of $\mathrm{Bi}_{2} \mathrm{WO}_{6} / \mathrm{NSTO} 10(83.3 \mathrm{k} \Omega)$ is smaller than that of $\mathrm{Bi}_{2} \mathrm{WO}_{6}(136 \mathrm{k} \Omega)$ or $\mathrm{N}-\mathrm{SrTiO}_{3}(184 \mathrm{k} \Omega)$ alone, attributed to the accelerated formation of charge-transfer states and depletion layers within the nanocomposites through the internal electrostatic field in the heterojunction. The reduced resistance of $\mathrm{Bi}_{2} \mathrm{WO}_{6} / \mathrm{N}-\mathrm{SrTiO}_{3}$ suggested an increased transmission rate of photogenerated charge carriers. Fig. 11b shows the electrochemical Mott-Schottky plot of $\mathrm{Bi}_{2} \mathrm{WO}_{6}$ and $\mathrm{N}-\mathrm{SrTiO}_{3}$ films on a platinum electrode substrate. The positive slopes revealed a typical n-type characteristic for both $\mathrm{Bi}_{2} \mathrm{WO}_{6}$ and $\mathrm{N}-\mathrm{SrTiO}_{3}$. Thus, a Z-type $\mathrm{n}-\mathrm{n}$ heterojunction is constructed by assembling $\mathrm{N}-\mathrm{SrTiO}_{3}$ and $\mathrm{Bi}_{2} \mathrm{WO}_{6}$, in which the conduction band potential is $-0.28 \mathrm{eV}$ for $\mathrm{N}-\mathrm{SrTiO}_{3}$ and $0.43 \mathrm{eV}$ of $\mathrm{Bi}_{2} \mathrm{WO}_{6}$, respectively, in terms of the equivalence of the Fermi level and conduction band potential in an n-type semiconductor. According to the band gaps of $\mathrm{N}-\mathrm{SrTiO}_{3}(3.08 \mathrm{eV})$ and $\mathrm{Bi}_{2} \mathrm{WO}_{6}$ $(2.83 \mathrm{eV})$, their valence band $\left(E_{\mathrm{VB}}\right)$ positions are estimated to be 2.80 and $3.26 \mathrm{eV}$, respectively. Based on the above experiment, the probable mechanism for the photocatalytic removal of the mixed tetracycline and $\mathrm{Cr}(\mathrm{vI})$ ions over $\mathrm{Bi}_{2} \mathrm{WO}_{6} / \mathrm{N}-\mathrm{SrTiO}_{3}$ under visible light irradiation is described in Fig. 12. (1) Under visible light illumination, electrons $\left(\mathrm{e}^{-}\right)$are excited into the CB and holes located at the valence band of $\mathrm{N}_{-} \mathrm{SrTiO}_{3}$. The same occurs for $\mathrm{Bi}_{2} \mathrm{WO}_{6}$. (2) The conduction band potentials of $\mathrm{Bi}_{2} \mathrm{WO}_{6}$ and $\mathrm{N}-\mathrm{SrTiO}_{3}$ are higher compared with the reductive potential of $\mathrm{Cr}_{2} \mathrm{O}_{7}{ }^{2-} / \mathrm{Cr}^{3+}$ (1.27 eV versus $\left.\mathrm{NHE}\right)$, and thus they both exhibit reducing capacity for $\mathrm{Cr}(\mathrm{VI})$ to $\mathrm{Cr}(\mathrm{III})$ ions, which was demonstrated in the $\mathrm{Cr}(\mathrm{vr})$ reduction experiment. However, $\mathrm{N}-\mathrm{SrTiO}_{3}$ exhibited excellent reducing ability due to its high conduction band level, whereas the reducing activity of $\mathrm{Bi}_{2} \mathrm{WO}_{6}$ was poor due to its slightly lower conduction band compared to $\mathrm{N}-\mathrm{SrTiO}_{3}$ (Fig. 7). (3) On the other hand, the valence band potentials of N$\mathrm{SrTiO}_{3}$ and $\mathrm{Bi}_{2} \mathrm{WO}_{6}$ are all lower than the oxidation potential of TC $(-3.28 \mathrm{eV})$, as shown in Fig. S5. $\dagger$ As a result, the holes in the valence band of $\mathrm{N}-\mathrm{SrTiO}_{3}$ and $\mathrm{Bi}_{2} \mathrm{WO}_{6}$ could degrade TC directly. However, the valence band potential of $\mathrm{Bi}_{2} \mathrm{WO}_{6}$ is much lower than the redox potential of ${ }^{\circ} \mathrm{OH} / \mathrm{H}_{2} \mathrm{O}(2.73 \mathrm{eV}$ versus $\mathrm{NHE}$ ), indicating that its holes could transform $\mathrm{H}_{2} \mathrm{O}$ into ${ }^{\circ} \mathrm{OH}$ and then oxidize TC. This was confirmed by the radical-trapping experimental results. At the same time, $\mathrm{N}-\mathrm{SrTiO}_{3}$ exhibits poor performance for the oxidation of TC due to its not very low valence band energy. (4) If we combine the two separate components, band bending was not obvious, due to the close Fermi energy level in the present $n-n$ junction. The conduction band (CB) of $\mathrm{Bi}_{2} \mathrm{WO}_{6}$ was slightly shifted upwards. In this case, the redox abilities of each component were not changed very much, unlike in $\mathrm{p}-\mathrm{n}$ type junctions. ${ }^{20,21}$ As a result, while maintaining the greater transition tendency of the charges between $\mathrm{Bi}_{2} \mathrm{WO}_{6}$ and $\mathrm{N}-\mathrm{SrTiO}_{3}$, the reductive ability of $\mathrm{N}-\mathrm{SrTiO}_{3}$ did not obviously decrease. The same case is observed for the oxidative performance of $\mathrm{Bi}_{2} \mathrm{WO}_{6} \cdot{ }^{52}$ Therefore, the photogenerated charge carriers are effectively separated by the heterojunction between $\mathrm{Bi}_{2} \mathrm{WO}_{6}$ and $\mathrm{N}-\mathrm{SrTiO}_{3}$, and the photocatalytic activity is also significantly improved.

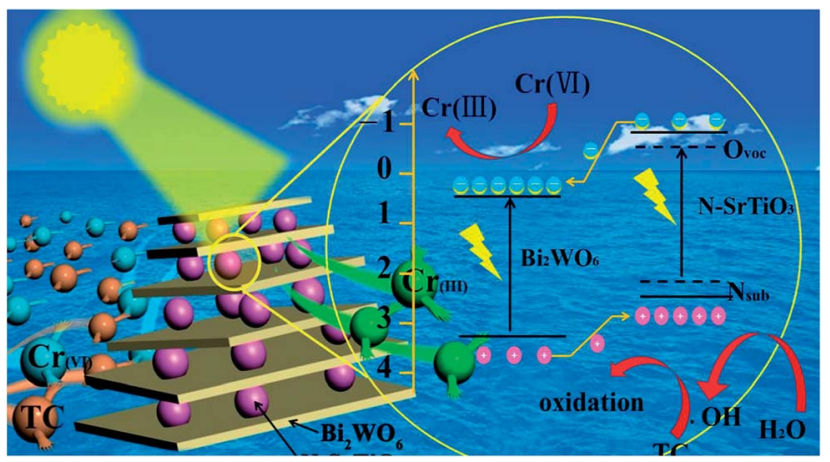

Fig. 12 Possible mechanism for $\mathrm{Cr}(\mathrm{VI})$ photoreduction and tetracycline oxidation over the $\mathrm{Bi}_{2} \mathrm{WO}_{6} / \mathrm{NSTO} 10$ photocatalytic system under visible light irradiation. 


\section{Conclusions}

In summary, we have successfully fabricated a series of $n-n$ $\mathrm{Bi}_{2} \mathrm{WO}_{6} / \mathrm{N}-\mathrm{SrTiO}_{3}$ heterojunctions with different mass ratios of $\mathrm{W}$ to $\mathrm{Ti}$ using a hydrothermal method. The as-prepared samples were composed of massive $\mathrm{N}-\mathrm{SrTiO}_{3}$ nanoballs with a diameter of about 10-20 nm, segmented by a small amount of $2 \mathrm{D}$ interlaced $\mathrm{Bi}_{2} \mathrm{WO}_{6}$ nanosheets. As established in the UV-vis experiment, the capacity to absorb visible light was significantly improved in the composite. Moreover, this $\mathrm{Bi}_{2} \mathrm{WO}_{6} / \mathrm{N}-\mathrm{SrTiO}_{3}$ composite showed obviously superior visible light photocatalytic efficiency and stability for the simultaneous removal of tetracycline and $\mathrm{Cr}(\mathrm{vI})$ compared with the individual $\mathrm{Bi}_{2} \mathrm{WO}_{6}$ or $\mathrm{N}-\mathrm{SrTiO}_{3}$, confirming that the high reductive and oxidative ability could be holistically improved through coupling design. This is particularly useful for the remediation of mixed contaminants in complicated aquatic environments. The results of free radical trapping experiments revealed that photoexcited $\mathrm{h}^{+}$and $\mathrm{e}^{-}$were responsible for the oxidation of TC and reduction of $\mathrm{Cr}(\mathrm{vI})$ ions, respectively. The $\mathrm{Z}$ type $\mathrm{n}-\mathrm{n}$ heterojunction of $\mathrm{Bi}_{2} \mathrm{WO}_{6} / \mathrm{N}-\mathrm{SrTiO}_{3}$ exhibited an excellent bipolar photo-oxidative and photo-reductive ability, while retaining a good visible light response, and simultaneously promoted the separation of the photogenerated electron-hole pairs. The present work could offer a new strategy to develop more efficient binary catalysts for practical application in the elimination of pharmaceutical and heavy metal pollutants in aquatic environments.

\section{Conflicts of interest}

There are no conflicts to declare.

\section{Acknowledgements}

This work was financially supported by the National Natural Science Foundation of China (Grants 21567017 and 21777078), the open project of the state key laboratory of inorganic synthesis and preparative chemistry of Jilin University (201610), and the Project of Research and Development of the Applied Technology for Inner Mongolia 2017.

\section{References}

1 R. Hirsch, T. Ternes, K. Haberer and K. Kratz, Sci. Total Environ., 1999, 225(1-2), 109-118.

2 B. Li and T. Zhang, Water Res., 2013, 47, 2970-2982.

3 A. Sarmah, M. Meyer and A. Boxall, Chemosphere, 2006, 65(5), 725-759.

4 J. Bound and N. Voulvoulis, Chemosphere, 2004, 56(11), 1143-1155.

5 T. Wang, W. Liu, L. Xiong, N. Xu and J. Ni, Chem. Eng. J., 2013, 215-216, 366-374.

6 X. Yu, Z. Lu, D. Wu, P. Yu, M. He, T. Chen, W. Shi, P. Huo, Y. Yan and Y. Feng, React. Kinet., Mech. Catal., 2014, 111, 347-360.
7 L. Minh, N. Khan, J. Drewes and R. Stuetz, Water Res., 2010, 44, 4295-4323.

8 T. Aarthi and G. Madras, Catal. Commun., 2008, 9(5), 630634.

9 D. Kolpin, E. Furlong, M. Meyer, E. Thurman, S. Zaugg, L. Barber and H. Buxton, Environ. Sci. Technol., 2002, 36, 1202-1211.

10 Q. Yuan, L. Chen, M. Xiong, J. He, S. Luo, C. Au and S. Yin, Chem. Eng. J., 2014, 255, 394-402.

11 F. Lian, Z. Song, Z. Liu, L. Zhu and B. Xing, Environ. Sci. Pollut. Res., 2013, 178, 264-270.

12 Z. Zhang, H. Liu, L. Wu, H. Lan and J. Qu, Chemosphere, 2015, 138, 625-632.

13 T. Yan, J. Tian, W. Guan, Z. Qiao, W. Li, J. You and B. Huang, Appl. Catal., B, 2017, 202, 84-94.

14 P. Huo, M. Zhou, Y. Tang, X. Liu, C. Ma, L. Yu and Y. Yan, J. Alloys Compd., 2016, 670, 198-209.

15 D. Ma, J. Wu, M. Gao, Y. Xin, T. Ma and Y. Sun, Chem. Eng. J., 2016, 290, 136-146.

16 X. Liu, Q. Lu and J. Liu, J. Alloys Compd., 2016, 662, 598-606. 17 P. Ju, Y. Wang, Y. Sun and D. Zhang, Dalton Trans., 2016, 45, 4588-4602.

18 Y. Xiang, P. Ju, Y. Wang, Y. Sun, D. Zhang and J. Yu, Chem. Eng. J., 2016, 288, 264-275.

19 X. Wang, S. Li, Y. Ma, H. Yu and J. Yu, J. Phys. Chem. C, 2011, 115(30), 14648-14655.

20 Y. Zhang, Y. Yu, X. Wang, G. Tong, L. Mi, Z. Zhu, X. Geng and Y. Jiang, J. Mater. Chem. C, 2017, 5, 140-148.

21 N. Zhang, Y. Zhang, X. Pan, M. Yang and Y. Xu, J. Phys. Chem. C, 2012, 116, 18023-18031.

22 K. Yu, C. Zhang, Y. Chang, Y. Feng, Z. Yang, T. Yang, L. Lou and S. Liu, Appl. Catal., B, 2017, 200, 514-520.

23 C. Zhang, K. Yu, Y. Feng, Y. Chang, T. Yang, Y. Xuan, D. Lei, L. Lou and S. Liu, Appl. Catal., B, 2017, 210, 77-87.

24 W. Dong, X. Li, J. Yu, W. Guo, B. Li, L. Tan, C. Li, J. Shi and G. Wang, Mater. Lett., 2012, 67, 131-134.

25 G. Xing, L. Zhao, T. Sun, Y. Su and X. Wang, SpringerPlus, 2016, 5, 1132.

26 W. Chen, T. Liu, T. Huang, X. Liu, J. Zhu, G. Duan and X. Yang, Appl. Surf. Sci., 2015, 355, 379-387.

27 J. Zhu, S. Liu, Q. Yang, P. Xu, J. Ge and X. Guo, Colloids Surf., A, 2016, 489, 275-281.

28 M. Li, L. Zhang, X. Fan, Y. Zhou, M. Wu and J. Shi, J. Mater. Chem. A, 2015, 3(9), 5189-5196.

29 D. Yue, D. Chen, Z. Wang, H. Ding, R. Zong and Y. Zhu, Phys. Chem. Chem. Phys., 2014, 16, 26314.

30 Y. Zhou, Y. Zhang, M. Lin, J. Long, Z. Zhang, H. Lin, J. Wu and X. Wang, Nat. Commun., 2015, 6, 8340.

31 Y. Huang, S. Kang, Y. Yang, H. Qin, Z. Ni, S. Yang and X. Li, Appl. Catal., B, 2016, 196, 89-99.

32 J. Xu, Y. Wei, Y. Huang, J. Wang, X. Zheng, Z. Sun, L. Fan and J. Wu, Ceram. Int., 2014, 40, 10583-10591.

33 L. Chen, D. Jiang, T. He, Z. Wu and M. Chen, CrystEngComm, 2013, 15(37), 7556-7563.

34 M. Sun, D. Li, W. Zhang, Z. Chen, H. Huang, W. Li, Y. He and X. Fu, J. Phys. Chem. C, 2009, 113, 14916-14921. 
35 L. Qu, J. Lang, S. Wang, Z. Chai, Y. Su and X. Wang, Appl. Surf. Sci., 2016, 388, 412-419.

36 L. Ye, X. Jin, C. Liu, C. Ding, H. Xie, K. Chu and P. Wong, Appl. Catal., B, 2016, 187, 281-290.

37 S. Kumar, S. Tonda, A. Baruah, B. Kumar and V. Shanker, Dalton Trans., 2014, 43, 16105-16114.

38 J. Li, H. Hao and Z. Zhu, Mater. Lett., 2016, 168, 180-183.

39 H. Li, Q. Deng, J. Liu, W. Hou, N. Du, R. Zhang and X. Tao, Catal. Sci. Technol., 2014, 4, 1028-1037.

40 L. Zhang, W. Tian, Y. Chen, J. Chen, H. Teng, J. Zhou, J. Shi and Y. Sun, RSC Adv., 2016, 6, 83471.

41 M. Liu, G. Lv, L. Mei, X. Wang, X. Xing and L. Liao, Adv. Mater. Sci. Eng., 2014, 2014, 409086.

42 H. Xu, W. Zhang, M. Ding and X. Gao, Mater. Des., 2017, 114, 129-138.

43 L. Liu, C. Luo, J. Xiong, Z. Yang, Y. Zhang, Y. Cai and H. Gu, J. Alloys Compd., 2017, 690, 771-776.
44 J. Qu, D. Chen, N. Li, Q. Xu, H. Li, J. He and J. Lu, Appl. Catal., $B, 2017,207,404-411$.

45 M. Naimi-Joubani, M. Shirzad-Siboni, J. K. Yang, M. Gholami and M. Farzadkia, J. Chem. Eng., 2015, 22, 317-323.

46 M. Cao, P. Wang, Y. Ao, W. Chao, J. Hou and Q. Jin, J. Colloid Interface Sci., 2016, 467, 129-139.

47 P. Huo, Z. Ye, H. Wang, Q. Guan and Y. Yan, J. Alloys Compd., 2017, 696, 701-710.

48 Z. Ye, J. Li, M. Zhou, H. Wang, Y. Ma, P. Huo, L. Yu and Y. Yan, Chem. Eng. J., 2016, 304, 917-933.

49 Y. Su, L. Hou, C. Du, L. Peng, K. Guan and X. Wang, RSC Adv., 2012, 2, 6266.

50 B. Luo, D. Xu, D. Li, G. Wu, M. Wu, W. Shi and M. Chen, ACS Appl. Mater. Interfaces, 2015, 7, 17061-17069.

51 S. Zhang, J. Li, M. Zeng, G. Zhao, J. Xu, W. Hu and X. Wang, ACS Appl. Mater. Interfaces, 2013, 5, 12735-12743.

52 J. Lee, Y. Kim, J. Kim, S. Kim, D. Min and D. Jang, Appl. Catal., B, 2017, 205, 433-442. 